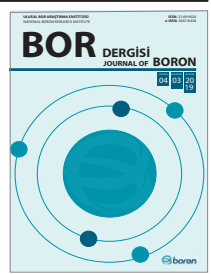

\title{
Synthesis and characterization of trimethoxy boroxine
}

\author{
Sedat Sürdem* \\ *National Boron Research Institute, Ankara, Turkey, ORCID ID orcd.org/0000-0001-8220-7934
}

\section{ARTICLE INFO}

Article history:

Received 02 August 2019

Revised form 16 September 2019

Accepted 19 September 2019

Available online 30 September 2019

\section{Research Article}

DOI: $10.30728 /$ boron.600813

Keywords:

Trimetoxy boroxine,

Boroxine,

Azeotropic distillation

Organoboron compound.

\begin{abstract}
Trimethoxy boroxine is used in fire extinguishing tubes because of its smoke suppressant properties and it is also used as an auxiliary catalyst in olefin polymerization, in lithium ion cells as an electrolyte additive, in welding and soldering works, in protective coating production and in hardening of epoxide resins. It has become a desirable material because of its superior properties and it has gained importance how to synthesize it cheaper and easier. In this study, trimethoxy boroxine was synthesized from the reactions of boric acid and trimethyl borate. In the first step, boric acid reacted with methanol in order to obtain trimethyl borate as a precursor. The best reaction yield was obtain by using 1:2 ratio of boric acid and trimethyl borate in cyclohexane. Trimethoxy boroxine was synthesized from boric acid and trimethyl borate in azeotropic

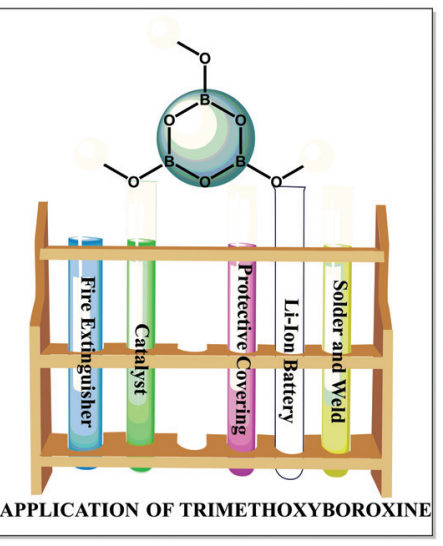
distillation set-up containing Dean-Stark apparatus. It was characterized by H-NMR and FT-IR.
\end{abstract}

\section{Introduction}

Boroxines are compounds whose molecular shapes are trimeric with six-membered ring consisting of successive boron and oxygen atoms. The electronic structures of boroxines are similar with the borazine ring. The electron delocalization on the ring is very weak due to the highly polar B-O bonds [1]. It is a critical material in many different fields especially in industrial production and applications. Some of these are fume suppressor, olefin polymerization [2] catalyst in welding and soldering processes, polishing of epoxy resin, polycarbonate production, protective coating production [3] and electrolyte additive in lithium ion batteries [4].

Boroxine structures may contain halogens, hydroxy or organic groups. The smallest member of boroxine derivatives is not stable and converts to diborane gas and boron trioxide as the decomposition product. Stable structure can be achieved by descending the temperatures to low values. Other boroxine derivatives can be synthesized by adding a halogen-to-link to the boroxine ring. The trihalogen boroxines having unstable structures like the smallest member can be characterized and solidified by cooling the temperature at $-135^{\circ} \mathrm{C}[5]$. In the literature, trihalogen boroxines are known to be unstable at room temperature and can be isolated and characterized at room temperature with their borontrihalide forms $[6,7]$.

Trihydroxy boroxine represents the structure of $\alpha-\mathrm{HBO}_{2}$ in the borontrioxide/water system. Trisorganyloxy, organic group bound boroxines, are esterified derivatives of trihydroxy boroxines (orthorhombic metaboric acid). As it is known, metaboric acid having a trimeric molecular shape is present in a functionalized manner in the boroxine ring [8]. Trimeric structure of trihydroxyboroxine has been characterized by Infrared (IR), Raman Spectroscopy and its molecular weight has been determined by HR-MS. Most of the trisorganyloxy boroxines are colorless hydroscopic compounds in liquid form. Moreover, solid forms of boroxine structures can be achieved by engineering of organic aliphatic or aromatic groups [9].

One of the purification methods of trisorganyloxy boroxines is distillation, but highly pure product cannot be obtained due to degradation at distillation temperatures. Another obstacle that can be countered while obtaining highly purified trisorganyloxy boroxines is their affinity to water. Boroxines can be degraded by hydrolysis even in humidity of air. Because of all these reasons, trisorganyloxy boroxines cannot be obtained at high purity. Among the organyloxy boroxines, the most widely studied compounds are those in which 
the organic group is alkyl (alkylolsi boroxine) and aryl (aryloxy boroxine). Among those, methyl, isopropyl, and butyl containing organyloxyboroxines have great importance. Especially, trimethoxy boroxine has the largest usage area. The most important reason is that trimethoxy boroxine leads to the production of alkylolysis boroxine, aryloxy boroxine and other boroxine derivatives by means of various chemical reactions. The most notable of these chemical reactions is transesterification. By the reaction of trimethoxy boroxine with an aryl or alkyl alcohol, it is possible to obtain the desired boroxine derivatives.

It is feasible to obtain trimethyl boroxine by many chemical methods. Azeotropic distillation is one of the most striking method for isolation of mixtures due to its high efficiency [10]. The first synthesis of trimethoxy boroxine was carried out in 1867 by Schiff. $\mathrm{H}$ et al. It can be obtained by exothermic reaction of boron trioxide and trimethylborate as well as by the reaction between boric acid and methanol. Trimethyl borate and boron tribromide reaction is known to be obtained with high yield [11]. However, the best results in terms of high yield and cheap cost are obtained by the reaction between trimethyl borate and boric acid. This reaction is modified to an azeotropic distillation set-up with a Dean-Stark apparatus to increase the reaction efficiency by removing the by-product (methanol). The most important significancy is that the used solvent does not mix with the formed by-product. Furthermore, its density is lower than the formed by-product. Trimethoxy boroxine pioneers the synthesis of other boroxine derivatives. Its industrial production finds a wide range era. Trimethoxy boroxine, known as a fire extinguisher or smoke suppressant, returns to borontrioxide form by combustion, especially in fires caused by powder zinc and powdered sodium metals. By covering the metals with trimethoxy boroxine in this form, the connection between metal and oxygen is cut and the combustion is prevented $[12,13]$. The use of trimethoxy boroxine as a catalyst in olefin polymerization is an another interest in applications. In olefin polymerizations where metallocene based single-site is used, trimethoxy boroxine is used as cocatalyst. In this way, it is determined that molecular weight is controlled in olefin polymerizations [2].

In this work, the synthesis of trimethoxy boroxine was studied. Cyclohexane was used as a proper solvent for the first time rather than common solvents such as toluene and hexane. Moreover, the Dean-Stark apparatus is applied in order to increase the reaction yield. Their characterizations were performed by using NMR and FTIR spectroscopy methods.

\section{Materials and methods}

All chemicals were purchased from Sigma- Aldrich Chemical Co. Ltd. and used without any further purification. The synthesized molecules were characterized via nuclear magnetic resonance (NMR) in deuterated chloroform. The chemical shifts were reported in ppm by taking tetramethylsilane as the internal reference. Fourier-transform infrared spectroscopy (FT-IR) were also used in characterization of the molecules. $\mathrm{KBr}$ window was applied for liquid form and $\mathrm{KBr}$ disc for solid form.

\subsection{Synthesis of trimetyl borate}

Boric acid $(250 \mathrm{~g}, 4.04 \mathrm{~mol})$ and methanol $(515 \mathrm{~mL}$, $20.20 \mathrm{~mol}$ ) were placed into $3 \mathrm{~L}$ reactor system and the temperature was raised to $70{ }^{\circ} \mathrm{C}$ and stirred for 3h (Figure 1a). Lithium chloride was partially added to trimethyl borate/methanol azeotropic mixture till phase separation was observed. They were separated by extraction funnel in order to obtain product as colorless liquid (160 g, yield 48\%); ${ }^{1} \mathrm{H}$ NMR $\left(\mathrm{CDCl}_{3}, 400 \mathrm{MHz}\right.$, ঠ) 3.40 (s, $1 \mathrm{H})$ FT-IR: $3200-3400 \mathrm{~cm}^{-1}$ (B-O-H partial), $3000-2800 \mathrm{~cm}^{-1}$ (alphatic C-H), $1550-1410 \mathrm{~cm}^{-1}\left(\mathrm{C}-\mathrm{H}_{3}\right.$ deformation modes), $1390 \mathrm{~cm}^{-1}$ (B-O) $1040 \mathrm{~cm}^{-1}$ (B-H links at non-apical positions).
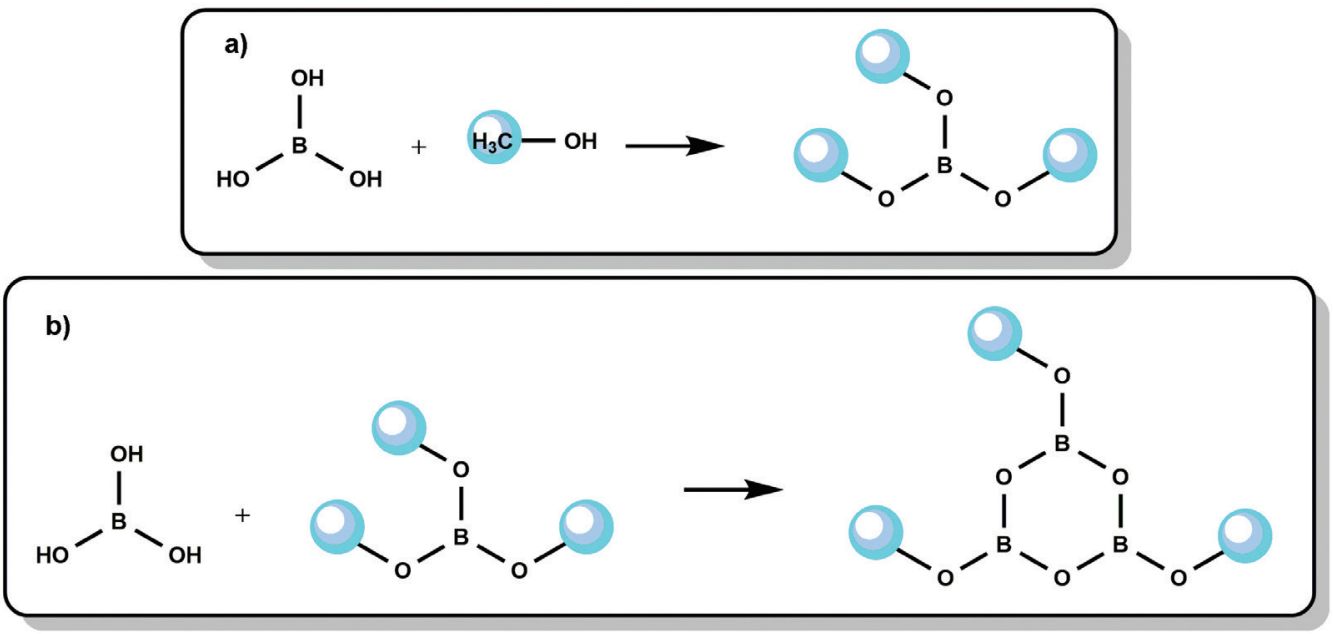

Figure 1. Synthetic routes for trimetoxy borate and trimetoxy boroxine. 


\subsection{Synthesis of trimetoxy boroxine}

A list of the solvents (Table 1) was tried in the synthesis of trimetoxy boroxine and the best result was obtained for cyclohexane. A reactor system with $3 \mathrm{~L}$ was filled with boric acid $(62 \mathrm{~g}, 1.02 \mathrm{~mol})$ and trimethyl borate (107 g, $2.05 \mathrm{~mol}$ ) in $515 \mathrm{~mL}$ cyclohexane (Figure 1b). Then, a $500 \mathrm{~mL}$ of Dean-Stark apparatus was placed into reactor flask. The mixture was stirred at reflux for $3 \mathrm{~h}$. The reaction was monitored by collected methanol amount in the Dean-Stark (about $120 \mathrm{~mL}$ ). Cyclohexane was removed under reduced pressure and the desired product was obtained as colorless sticky solid (201 g, yield 92\%); ${ }^{1} \mathrm{H}$ NMR $\left(\mathrm{CDCl}_{3}, 400 \mathrm{MHz}, \delta\right) 3.70$ (s, $1 \mathrm{H}$ ), FT-IR: $3000-2800 \mathrm{~cm}^{-1}$ (aliphatic C-H), 1550$1410 \mathrm{~cm}^{-1}\left(\mathrm{C}-\mathrm{H}_{3}\right.$ deformation modes), $1320 \mathrm{~cm}^{-1}(\mathrm{~B}-\mathrm{O})$, $1250 \mathrm{~cm}^{-1}$ (B-O-B), $1080 \mathrm{~cm}^{-1}$ (B-H links at non-apical positions).

\section{Results and discussion}

In the first step of this study, commercially purchased boric acid and methanol were reacted under appropriate reaction conditions to obtain trimethyl borate (Figure1a). The ${ }^{1} \mathrm{H}$ NMR spectrum of the structure (Figure 2) shows that the singlet peak at $3.42 \mathrm{ppm}$ represents the presence of protons of the methyl group bound to boric acid. In addition, FT-IR spectrometer depicts the peak at the frequency of $3200-3400 \mathrm{~cm}^{-1}$ which belongs to partial $\mathrm{B}-\mathrm{O}-\mathrm{H}$ bonds, while the peaks in the frequency range of $3000-2800 \mathrm{~cm}^{-1}$ aliphatic $\mathrm{C}-\mathrm{H}$. Moreover, boron-oxygen tension band peaks were observed at $1390 \mathrm{~cm}^{-1}$ and $\mathrm{B}-\mathrm{H}$ links at non-apical positions gives response at $1040 \mathrm{~cm}^{-1}$ (Figure 3 ).

Successfully synthesized trimethyl borate was used in the next step for synthesis of trimethoxy boroxine (Figure $1 \mathrm{~b})$. As known in the literature, trimetoxy boroxine is a material which can hydrolyze with moisture and decomposes when exposed to high temperature during purification processes. Therefore, temperature, synthesis stoichiometry and selected solvent are important parameters of reaction conditions. Water, methanol and the like are condensation by-products formed in the synthesis of alkoxy or aryloxy boroxines. These by-products result in the synthesis of the synthesized trimethoxy boroxine and derivatives by hydrolysis and conversion to the starting materials. There is a need for special systems to prevent the return of boroxine derivatives formed by reaction. Dean-Stark apparatus is conveniently positioned in an azeotropic distillation set-up to remove condensation by-products.
In this study, many stoichiometries have been tried and the most suitable reaction conditions have been found to be $1: 2(\mathrm{~mol} / \mathrm{mol})$ ratio for boric acid to methanol as depicted in Table 1.

As mentioned before, the solvent has a huge effect on reaction yield. Toluene, n-hexane, cyclohexane, $x y$ lene and chlorobenzene were chosen as solvents. Trimethoxy boroxine formation was observed at low yield and long reaction time in solvents having high boiling point (toluene, xylene and chlorobenzene) while providing reaction conditions. The main reason for this is thought to be caused by the degradation of boroxine and its derivatives at elevated temperatures. In addition, it has been observed that the condensation byproduct methanol formed is mixed with the solvents mentioned above, thus reducing the reaction efficiency. When the reaction was carried out with $n$-hexane, provided that the stoichiometry was the same, the reaction yield increased relatively to the aromatic solvents we tested. The main reason for this is the removal of methanol from the reaction medium by means of the Dean-Stark apparatus, since it does not mix with hexane. However, considering the increase in reaction time and the amount of energy consumed during the reaction, it was found to be not an economical method because the boiling point of $n$-hexane was lower than the boiling point of methanol, so it took time to collect the heterogeneous mixture formed in the Dean-Stark apparatus. One of the most important parameters for this reaction was the need for a solvent which is immiscible with methanol, has a higher boiling point than methanol and can reach boiling point under decomposition temperature. Cyclohexane has a boiling point of $88^{\circ} \mathrm{C}$ and does not mix with methanol, proving to be the most suitable solvent for these conditions in this work.

The reaction with the cyclohexane was collected in the Dean-Stark apparatus (methanol) by-product expected to occur in the reaction within 1-1.5 hours and the reaction was carried out in about $100 \%$ yield. The synthesized trimethoxy boroxine was characterized by FT-IR and ${ }^{1} \mathrm{H}-\mathrm{NMR}$ and the structure was determined. The ${ }^{1} \mathrm{H}$ NMR spectrum of the structure (Figure 2) shows that the singlet peak at $3.74 \mathrm{ppm}$ shows the protons of the methyl group in the structure of trimethoxy boroxine. When the proton spectrums of trimethyl borate and trimethoxy boroxine are compared, the protons of trimethoxy boroxine were shifted to low field region. In the boroxine ring, the number of oxygen is

Table 1. Optimization studies of trimethoxy boroxine synthesis.

\begin{tabular}{lccc}
\hline Solvent & Temperature $\left({ }^{\circ} \mathbf{C}\right)$ & Collected Methanol $(\mathbf{m L})$ & Time $(\mathbf{h})$ \\
\hline Toluene & 130 & 42 & 24 \\
n-Hexane & 70 & 90 & 6 \\
Cyclohexane & 90 & $\sim 120$ & 3 \\
Xylene & 140 & 60 & 24 \\
Chlorobenzene & 190 & 60 & 24 \\
\hline
\end{tabular}




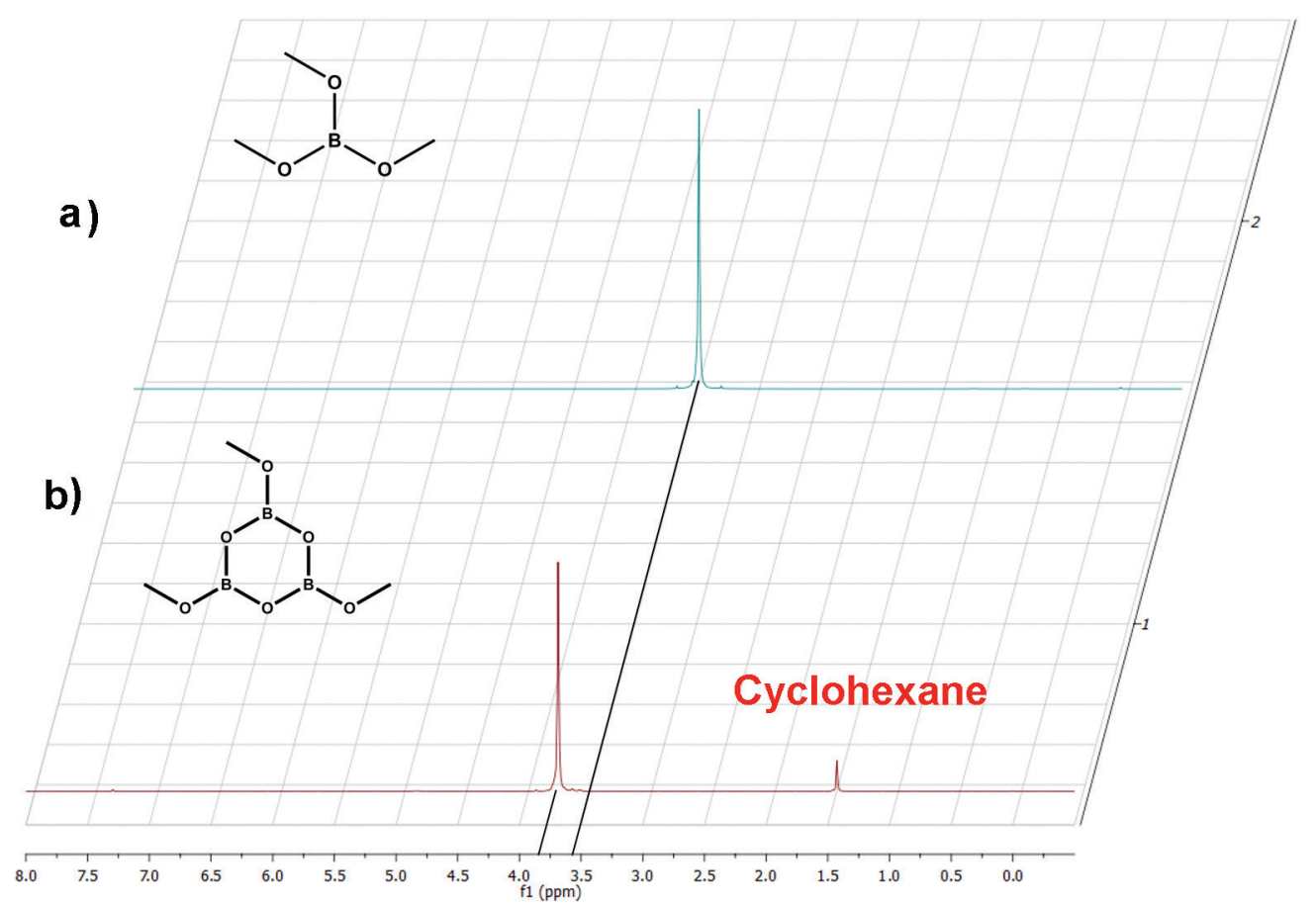

Figure 2. ${ }^{1} \mathrm{H}$ spectrum of trimethyl borate a) and trimethoxy boroxine $\mathrm{b}$ ).

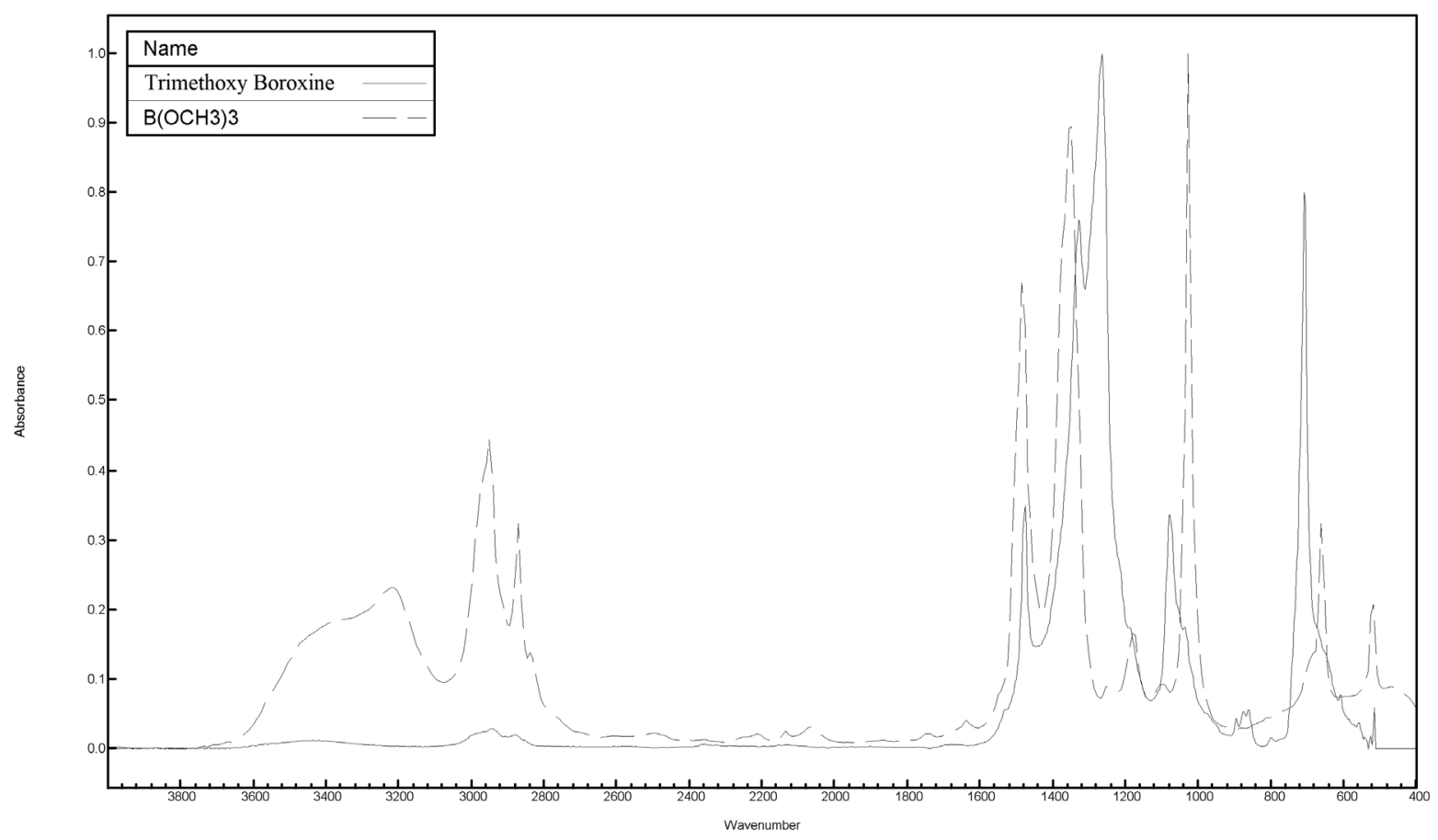

Figure 3. FT-IR spectrum of trimethyl borate and trimethoxy boroxine.

increased and this leads to an increase in the electron density toward to boroxine ring from the terminal methyl protons since the singlet peak shift from 3.42 ppm to $3.74 \mathrm{ppm}$.

Additionally, the structure was characterized from FTIR spectrum. Aliphatic $\mathrm{C}-\mathrm{H}$ bonding arises in the range of $3000-2800 \mathrm{~cm}^{-1}$ while deformation modes of $\mathrm{C}-\mathrm{H}_{3}$ were observed at $1550-1410 \mathrm{~cm}^{-1}$. Further, $1320 \mathrm{~cm}^{-1}$ represent $\mathrm{B}-\mathrm{O}$ bond while $\mathrm{B}-\mathrm{O}-\mathrm{B}$ bonds in the ring structure is seen at $1250 \mathrm{~cm}^{-1}$. A non-apical positions of $\mathrm{B}-\mathrm{H}$ links is observed at $1080 \mathrm{~cm}^{-1}$ (Figure 3).

\section{Conclusions}

In this study, trimetoxy boroxine was synthesized by starting with trimetyl borate as a precursor. As known from the literature, trimetoxy boroxine is used in order to synthesize the most of the common alkylated or aromatic alkoxy boroxine derivatives. The most important problem faced with is the distillation temperature where trimetoxy boroxine gets decomposed at that temperature.

In order to solve this problem, a solvent having a boiling 
point lower than the distillation temperature of trimethoxy boroxine should be used, and this solvent should be immiscible with the reaction byproduct of methanol. Dean-Stark apparatus was used to remove the methanol, which can hydrolyze trimethoxy boroxine, and to increase the yield of the reaction. The solvent was selected with higher boiling point than methanol since methanol hydrolysis our desired product.

\section{Acknowledgment}

Thanks to Soner Öztürk and Kardelen Göksu for their contributions and to National Boron Research Institute for laboratory facilities.

\section{References}

[1] Coulson C. A., Dingle T. W., The B-O bond lengths in boron-oxygen compounds, Acta Crystallogr. Sect. B Struct. Crystallogr. Cryst. Chem., 24, 153-155, 1968.

[2] Welch M. B., United States patent, Geothermics, 14, 595-599, 1985.

[3] Delpierre S., Willocq B., De Winter J., Dubois P., Gerbaux P., Raquez J. M., dynamic Iminoboronate-based boroxine chemistry for the design of ambient humiditysensitive self-healing polymers, Chem. A Eur. J. 23, 6730-6735, 2017.

[4] Kalemos A., The nature of the chemical bond in borazine $\left(\mathrm{B}_{3} \mathrm{~N}_{3} \mathrm{H}_{6}\right)$, boroxine $\left(\mathrm{B}_{3} \mathrm{O}_{3} \mathrm{H}_{3}\right)$, carborazine $\left(\mathrm{B}_{2} \mathrm{~N}_{2} \mathrm{C}_{2} \mathrm{H}_{6}\right)$, and related species, Int. J. Quantum Chem., 118, e25650 2018.

[5] Fisher H. D., Lehmann W. J., Shapiro I., Trifluoro- boroxine: Preparatıon, infrared spectrum and structure 1., J. Phys. Chem., 65, 1166-1168, 1961.

[6] Farber M., Heat of formation and entropy of the trimer of boron oxyfluoride, J. Chem. Phys. 36, 661-664, 1962.

[7] Latimer B., Devlin J. P., Vibrational spectra of fluorine and chlorine derivatives of boroxine-II, Spectrochim, Acta Part A Mol. Spectrosc., 23, 81-88, 1967.

[8] Seyferth D., Gmelin Handbuch der Anorganischen Chemie, Erganzungsband zur 8. Auflage, Vol. 13, Borverbindungen, Teil 1, Binare B-N Verbindungen, B-N-C Heterocyclen, Polymere B-N Verbindungen, J. Organomet. Chem., 1974.

[9] Köster R., Organoboron Chemistry. VonH. Steinberg. Band 1: Boron-Oxygen and Boron-Sulfur Compounds. Interscience Publishers, A Division of John Wiley \&amp; Sons, Inc., New York-London-Sidney 1964. 1. Aufl., XXXII, 950 S., zahlr. Tab., geb. £ 12.8.0. Angew. Chemie 77, 108-108, 1965.

[10] Wilcox N. J., Kwochka W. R., Phenyl Replacement Reactions : Solvent Effects on Reactions of Boroxines with Primary Amines, 2015.

[11] Lappert M. F., 568. Cyclic organic boron compounds. Part I. Preparation, characterisation, and stability of esters of metaboric acid, J. Chem. Soc., 27901958.

[12] Boroxine Derivatives as flame retardant, WO 2006/089937 A1, 2006.

[13] Commerford J. D. Chamberlain D. L., Shepherd J. W., Trimethoxy boroxine-An Extinguishing Agent for Metal Fires, Adv. Chem., 23,158-162, 1959. 